\title{
Eventos da IUPAC Austrália 2001
}

No período de 29/6/2001 a 8/7/2001 tiveram lugar em Brisbane, Austrália, a $41^{\text {st }}$ General Assembly e o World Chemistry Congress, da IUPAC. Paralelamente à General Assembly ocorreram as últimas reuniões de trabalho das três comissões que compõem a Macromolecular Division - MMD, já que o esquema de funcionamento das várias Divisões da IUPAC será significativamente alterado a partir de 01/01/2002.

No que respeita a MMD, um novo Comitê foi eleito e toma posse em 01/01/2002, ficando assim constituído: Presidente: R. Stepto (UK); Vice-Presidente: Jung-Il Jin (Coréia); Presidente Passado: R. Gilbert (Austrália); Secretário: W. Work (EUA); Membros Titulares (TMs): M.Barón (Argentina), M. Hess (Alemanha); K. Horie (Japão), R. Jones (UK), P. Kubisa (Polônia) e M. Laun (Alemanha); Membros Associados (AMs): D. Berek (Eslovaquia), M. Buback (Alemanha), A. Khokhlov (Rússia), S. Penczek (Polônia), D. Tabak (Brasil), J. Vohlidal (RepúblicaTcheca) e F. Wang (China).

Por indicação do Prof. Robert Stepto, a partir de janeiro de 2002 estarei participando da Coordenação de Educação da MMD e como seu representante na CHEMRAWN. Vale ressaltar que a IUPAC permite que o Comitê da Divisão aceite até 6 (seis) Representantes Nacionais (NRs), desde que sejam de países não representados no Comitê. Tais NRs devem ser indicados pelas NAOs (detalhes no site www.iupac.org/divisions/ IV/index.html). Em 2002 todas as atividades das Divisões da IUPAC se darão através de projetos que deverão ter Coordenador(es) e Grupo de Trabalho. Esses agrupamentos que se darão em torno de um projeto terão o nome de Grupos de Trabalho, Sub-comitê ou análogo e deverão ser aprovados pelo Comitê da Divisão. Aqueles interessados em apresentar projetos na área de Polímeros e a criação de Grupos de Trabalho poderão dirigir correspondência ao Prof. David Tabak (dtabak@far.fiocruz.br ou tabak@uninet.com.br). Infelizmente os nomes dos participantes dos novos projetos aprovados não sairão na próxima edição do Blue Book, já que o prazo para o fechamento da mesma é setembro/2001. Já manifestaram informalmente interesse nesse tipo de proposta, grupos que atualmente estão envolvidos nas áreas de terminologia, propriedades mecânicas, cinética e caracterização.

Nos dias 7 e 8 de julho de 2001 teve lugar a Reunião do Conselho da IUPAC onde tive a oportunidade de representar o Brasil, juntamente com as pesquisadoras Myrna Sabino e Carol H. Collins (Chefe da Delegação). Na ocasião foi eleito o futuro Presidente da IUPAC, L.K. Sydnes da Noruega. Entre vários outros assuntos, foi aprovada a criação da Divisão de Nomenclatura, cujo Presidente será Alan D. McNaught. Da MMD a nova Divisão absorverá a nomenclatura de polímeros baseada na estrutura "structure based nomenclature". A nomenclatura baseada na fonte "source based nomenclature" continuará sendo cuidada pela MMD. É importante ainda ressaltar que minha participação nos eventos acima foi inteiramente custeada por Far-Manguinhos/Fiocruz.

A próxima reunião da MMD terá lugar em Beijing, China, em julho de 2002, onde também ocorrerá o Macro-2002 (World Polymer Congress). Naquela reunião o Brasil deverá apresentar os preparativos para a realização do Macro-2006, em nosso País.

Notícia elaborada pelo Prof. David Tabak, Instituto de Tecnologia em Fármacos - Far-Manguinhos/Fiocruz, Rio de J aneiro, RJ , E-mail: dtabak@ far.fiocruz.br 